Kansas State University Libraries

New Prairie Press

Conference on Applied Statistics in Agriculture 2009 - 21st Annual Conference Proceedings

\title{
APPLICATION OF THE DYA METHOD TO COMPARE WHEAT CULTIVAR YIELDS
}

Arlin Feyerherm

Allan Fritz

Follow this and additional works at: https://newprairiepress.org/agstatconference

Part of the Agriculture Commons, and the Applied Statistics Commons

\section{(c) $(1) \Theta \Theta$}

This work is licensed under a Creative Commons Attribution-Noncommercial-No Derivative Works 4.0 License.

\section{Recommended Citation}

Feyerherm, Arlin and Fritz, Allan (2009). "APPLICATION OF THE DYA METHOD TO COMPARE WHEAT CULTIVAR YIELDS," Conference on Applied Statistics in Agriculture. https://doi.org/10.4148/

2475-7772.1079

This is brought to you for free and open access by the Conferences at New Prairie Press. It has been accepted for inclusion in Conference on Applied Statistics in Agriculture by an authorized administrator of New Prairie Press. For more information, please contact cads@k-state.edu. 


\author{
APPLICATION OF THE DYA METHOD TO COMPARE \\ WHEAT CULTIVAR YIELDS \\ Arlin Feyerherm and Allan Fritz ${ }^{1}$ \\ ${ }^{1}$ Professor Emeritus of Statistics and Professor of Agronomy, Kansas State University, \\ Manhattan, KS 66506
}

\begin{abstract}
At the 1998 conference, we proposed use of the DYA (differential yielding ability) method to compare the yielding ability of wheat cultivars. In this paper we review the method: its models and assumptions, and then show computation of sample statistics. An example will exhibit the output from performance trial yields when the method is applied in one of the nine ecogeographic areas of fall-planted wheat in the Midwest. Results of comparable outputs over years forecasted which cultivars would become popular with growers in Kansas
\end{abstract}

\title{
INTRODUCTION
}

Simple means and ranks have been the most widely used statistics to compare cultivars for yielding ability. The DYA (differential yielding ability) method is capable of producing probabilistic inference for future yielding ability from a sample of cultivar performance trials (CPT's) conducted at different locations over a number of seasons (crop-years). It addresses the problem of unbalanced data, partially removes unwanted environmental effects from entry comparisons, compares cultivars that were present for different time periods, has simple computational procedures, and is easy to update annually.

When applying the DYA method, all entries in a performance trial are compared with a standard which is the yield of a check cultivar (or mean of one of more checks). The DYA value of cultivar (A) is the difference between the yield of A and the standard. If cultivars (A and B) and a check (C) appear in CPT's at three locations for two seasons in an ecogeographic area, then six DYA values for A and six for B are available to compare how each performed against the check $C$.

The DYA method was formalized in Feyerherm, et.al. (1998) and was expanded with arguments supporting model assumptions and further application in Feyerherm, et.al. (2004). The idea of focusing on yield differences and using means of differences and their standard errors is certainly not new. It was used by Student in 1923; later labeled the "method of direct differences" and described, along with other statistical methods for cultivar testing, in Patterson (1997).

We have applied the DYA method to performance trials of winter and spring wheat cultivars. For purposes of discussion, we will confine our examples to the southern winter wheat region of Nebraska, Colorado, Kansas, Oklahoma, and Texas. This region was divided into nine ecogeographic areas for application. 


\section{BASIC STATISTICAL CONSIDERATIONS}

The physical observational unit was a seed lot with a given genetic makeup. The measure of interest was grain yield harvested from the seed lot when planted in plots in a CPT. A complex set of environmental factors has a major influence on yield. These factors include: (i) weather; (ii) soil properties; (iii) pests (diseases, insects, and weeds); and interaction of weather with the other two. The environmental effects on the yield of a trial entry are equivalent to a random draw from a population of such effects, and vary from location-to-location within and among seasons.

For our statistical model, we assumed that the DYA value for cultivar (v) for season (i) at location (j) was :

where,

$$
\begin{gathered}
\mathrm{DYA}_{\mathrm{ij}}(\mathrm{v})=\mu_{\mathrm{D}}(\mathrm{v})+\mathrm{S}_{\mathrm{i}}(\mathrm{v})+\mathrm{L}_{\mathrm{ij}}(\mathrm{v}) ; \\
\mathrm{i}=1,2, \ldots, \mathrm{N} ; \quad \mathrm{j}=1,2, \ldots, \mathrm{n} ; \quad \mathrm{v}=1,2, \ldots, \mathrm{V} ;
\end{gathered}
$$

$$
\begin{aligned}
\mu_{D}(v)= & \text { population mean DYA value for cultivar }(v), \\
\mathrm{S}_{\mathrm{i}}(\mathrm{v})= & \text { random environmental effects for season } \mathrm{i} \text {, which are normally and } \\
& \text { independently distributed with mean zero and variance } \sigma^{2}{ }_{\mathrm{S}}(\mathrm{v}) . \\
\mathrm{L}_{\mathrm{ij}}(\mathrm{v})= & \text { random environmental effects for location } \mathrm{j} \text { in season } \mathrm{i} \text {, which are } \\
& \text { normally and independently distributed with mean zero and } \\
& \text { variance } \sigma_{\mathrm{L}}^{2}(\mathrm{v}) .
\end{aligned}
$$

The $\mathrm{DYA}_{\mathrm{ij}}(\mathrm{v})$ values were assumed normally and independently distributed with mean $\mu_{D}(v)$ and variance $\left[\sigma_{L}^{2}(v)+\sigma_{S}^{2}(v)\right]$ for cultivar $(v)$. The $S_{i}(v)$ and $L_{i j}(v)$ values were assumed to be independent. The random behavior of environmental effects gave credence to the independence assumptions.

One might ask, is $\sigma_{s}^{2}(\mathrm{v})=0$ ? If so, a simpler model with $S_{\mathrm{i}}(\mathrm{v})=0$ would suffice. If not, then the simpler model would overestimate the number of degrees of freedom and underestimate standard errors of the means for multi-season data. Evidence that $\sigma_{s}^{2}(v)>0$ is given in Feyerherm et.al. (2004). Added evidence is shown in Table 1. This implies that, based on Eq.[1] , means, standard errors, and t-tests for cultivars in their first test year should be tested with (n-1) d.f. (Table 2) while those entries tested for more than one year would be evaluated based on a critical $t$ with ( $\mathrm{N}-1$ ) degrees of freedom (Table 3$)$.

\section{$\underline{\text { APPLICATIONS }}$}

For the past 10 years we have distributed a set of tables to wheat breeders and specialists showing results when the DYA method was applied to CPT's within each area of the nine different ecogeograpic areas in the southern winter wheat region. An example of results for the Central area of the southern winter wheat region is shown in Tables 2 and 3. SAS software was 
used to output tables, similar to Tables 2 and 3, for the nine ecogeographic areas. In the first stage of calculations, PROC MEANS was applied to the variable (DYA = D), by cultivar and season. For each season and cultivar the output was values of $\bar{D}, \mathrm{SD}(\mathrm{D}), \mathrm{SE}(\bar{D}), \mathrm{t}$, and $\mathrm{p}$. Table 2 shows the output for those cultivars which were only in trials in 2008. In the second stage, PROC MEANS was applied to the variable $(\bar{D})$, by cultivar. For each cultivar, the output was $\overline{\bar{D}}, \mathrm{SD}(\bar{D}), \mathrm{SE}(\overline{\bar{D}}), \mathrm{t}$, and $\mathrm{p}$ values and $\overline{\bar{D}}$ was the unweighted mean of $\bar{D}$ values from $\mathrm{N}$ seasons starting with 2008 and going back to 2003,

For a given cultivar, the number(n) of locations was not always the same for all $\mathrm{N}$ seasons but the robustness of the t-distribution gave good approximations for p-values [Feyerherm et.al. (2004)] in both single and multiple-season applications.

\section{$\underline{\text { ADOPTION OF CULTIVARS BY GROWERS }}$}

The Kansas Department of Agriculture publishes results of a yearly survey of wheat growers showing "percent of seeded acreage" of wheat cultivars. A quick glance of the tables over the past five years reveals that each year the top five cultivars accounted for (52-70)\% of the state acreage. The same distribution tends to hold within each of the nine Agricultural Statistics Districts (ASD's). The remaining acres were distributed among 25 or more cultivars so the distribution is very skewed.

To what extent is the rank of a wheat cultivar in the distribution of seeded acres forecasted by its $\overline{\bar{D}}$ value in prior years? Some insight can be gained by examining Tables 4 and 5 for two different regions in Kansas. A number of factors must be taken into account when considering popularity of a cultivar: (1) Unlike corn hybrids or (GMO) cultivars, a wheat grower does not have to buy new seed every year so incentives, such as higher yielding ability or other favorable traits, may be needed to adopt a newer cultivar; and (2) new cultivars released by public breeding programs tend to gain popularity quicker within the releasing state than cultivars from neighboring states..

'Jagger' was chosen as the check and provided the standard value for all $\overline{\bar{D}}$ values in Tables 4 and 5. It was released in 1994, became the most popular cultivar in Kansas in 1999, and topped out at $45.2 \%$ in 2003 . Since then, it lost seeded acres, first to 'Jagalene' then to other cultivars.

In Western Kansas (Table 4), Jagalene's $\overline{\bar{D}}$ was 6.5 bushels per acre (B/A) in 2004 and dropped to $2.8 \mathrm{~B} / \mathrm{A}$ by 2008 . 'TAM 111 ' with $\overline{\bar{D}}=5.0$ and 'TAM 112 ' with $\overline{\bar{D}}=9.5$ in the 2009 column moved into "top five" ranks in 2006 and 2008, respectively. 'TAM 110', 'Trego', 'Stanton', and 'Ike' with small or negative values of $\overline{\bar{D}}$ dropped out of the running for the "top five".

In South-central and Southeastern Kansas (Table 5), Jagger was \#1 in 2005 but lost that position to 'Overley' whose $\overline{\bar{D}}$ ranged from 11.8 to $6.5 \mathrm{~B} / \mathrm{A}$. 'Santa Fe' $(\overline{\bar{D}}=7.5)$, 'Fuller' 
$(\overline{\bar{D}}=5.8)$, and 'Postrock' ( $\overline{\bar{D}}=4.9)$, in the 2009 column, came into play. Cultivars ' 2174 ' and 'Omega' had negative $\overline{\bar{D}}$ 's and dropped from the top-five rankings.

Not seen in Tables 4 and 5 are cultivars with $\overline{\bar{D}}$ 's as large or larger than those shown. They were from private or out-state breeding programs which may not be accepted by growers as readily as those from in-state programs. Also, we have not shown standard errors of $\overline{\bar{D}}$ values in Tables 4 and 5 but one can get some idea of size from the $\operatorname{SE}(\overline{\bar{D}})$ column in Table 3 .

Finally, when examining Table 3, the sample size ( $\mathrm{N}=$ number of seasons) may not be large enough to declare a "significant difference" between a cultivar and the check(s). But, keep in mind, growers do not always have the luxury of waiting for statistical significance before making varietal decisions

\section{$\underline{\text { REFERENCES }}$}

Feyerherm, A.M., R.G. Sears, and J.J. Higgins. 1998. Statistical analysis of field varietal performance trials. Proceedings of the tenth annual conference on applied statistics in agriculture. Pages 22-31. KSU. Manhattan, Ks.

Feyerherm, A.M., G.M. Paulsen, and A.K. Fritz. 2004. A statistical method for summarizing results of cultivar performance trials. Agron. J. 96: 992-996.

Patterson, H.D. 1997. Analysis of series of variety trials. Pages 139-161. In R.A.

Kempton and P.N. Fox (ed.) Statistical methods for plant variety evaluation. Chapman and Hall, London.

\section{$\underline{\text { TABLES }}$}

Table 1. Estimated variance components for differences $\left[D Y A_{i j}(v)\right]^{*}$ and tests of signifance (pvalues) for 25 observations (five locations over five seasons) in north central and northeast Oklahoma. Units are bushels/acre..

\begin{tabular}{lrrr} 
CULTIVAR & $\hat{\boldsymbol{\sigma}}_{\mathbf{L}}^{2}$ & $\hat{\boldsymbol{\sigma}}_{\mathbf{S}}^{2}$ & $\mathrm{p}$-value \\
DELIVER & 78.4 & 64.5 & .005 \\
ENDURANCE & 42.2 & 45.0 & .001 \\
FANNIN & 61.1 & 34.7 & .018 \\
JAGGER & 9.3 & -0.3 & .524 \\
OVERLEY & 78.0 & 23.7 & .073 \\
\hline
\end{tabular}

* See Eq. [1]. 
Table 2. Dryland single season (2008) results for DYA analysis of performance trials of hard winter wheat in the Central (C) area (Fig. 1).

Standard was average yield of 'Jagalene' and 'Overley'.

$\begin{array}{lcrrrrr}\text { CULTIVAR } & \mathrm{n} & \bar{D} & \mathrm{SD}(\mathrm{D}) & \mathrm{SE}(\bar{D}) & \mathrm{t} & \mathrm{p} \\ & & -------- \text { bushels/acre------ } & & \\ \text { TAM 304 } & 2 & 15.00 & 4.24 & 3.00 & 5-00 & 0.13 \\ \text { ARMOUR } & 3 & 14.00 & 14.00 & 8.08 & 1.73 & 0.23 \\ \text { RUST BUSTER } & 3 & 13.67 & 6.51 & 3.76 & 3.64 & 0.07 \\ \text { TAM 203 } & 4 & 11.38 & 10.96 & 5.48 & 2.07 & 0.13 \\ \text { JACKPOT } & 7 & 10.36 & 8.91 & 3.37 & 3.08 & 0.02 \\ \text { RISING } & 6 & 1.17 & 4.11 & 1.68 & 0.70 & 0.52\end{array}$

Table 3. Dryland multi-season (2003-2008) results for DYA analysis of performance trials of hard winter wheat in the Central (C) area (Fig. 1). Standard was average yield of 'Jagalene' and 'Overley'.

\begin{tabular}{lcrrrrl} 
CULTIVAR & $\mathrm{N}$ & $\overline{\bar{D}}$ & $\mathrm{SD}(\bar{D})$ & $\mathrm{SE}(\overline{\bar{D}})$ & $\mathrm{t}$ & $\mathrm{p}$ \\
& & -12.75 & 2.24 & 1.58 & 8.05 & 0.08 \\
ART & 2 & 7.67 & 5.34 & 3.08 & 2.49 & 0.12 \\
FULLER & 3 & 7.35 & 2.97 & 2.10 & 3.50 & 0.18 \\
DUSTER & 2 & 7.35 & 0.18 & 0.13 & 56.22 & 0.01 \\
DOANS & 2 & 6.50 & 2.12 & 1.50 & 4.33 & 0.14 \\
SPARTAN & 2 & 6.25 & 4.60 & 3.25 & 1.92 & 0.31 \\
WINTERHAWK & 2 & 4.76 & 5.41 & 2.70 & 1.76 & 0.18 \\
SANTA FE & 4 & 3.70 & 5.01 & 2.89 & 1.28 & 0.33 \\
SHOCKER & 3 & 2.84 & 6.19 & 3.57 & 0.80 & 0.51 \\
POSTROCK & 3 & 2.70 & 6.10 & 2.73 & 0.99 & 0.38 \\
ENDURANCE & 5 & 2.58 & 1.59 & 1.13 & 2.29 & 0.26 \\
CENTERFIELD & 2 & 2.38 & 1.74 & 0.71 & 3.36 & 0.02 \\
OVERLEY & 6 & 1.72 & 4.27 & 2.14 & 0.81 & 0.48 \\
OK BULLET & 4 & 1.58 & 5.94 & 2.97 & 0.53 & 0.63 \\
STURDY 2K & 4 & 0.16 & 8.18 & 3.66 & 0.04 & 0.97 \\
DELIVER & 5 & -0.06 & 5.65 & 3.26 & -0.02 & 0.99 \\
TAM 111 & 3 & -0.53 & 12.51 & 5.11 & -0.10 & 0.92 \\
2137 & 6 & -1.23 & 9.48 & 4.74 & -0.26 & 0.81 \\
DANBY & 4 & -1.64 & 4.45 & 1.99 & -0.82 & 0.46 \\
FANNIN & 5 & -2.36 & 3.12 & 1.56 & -1.52 & 0.23 \\
PROTECTION & 4 & -2.38 & 1.74 & 0.71 & -3.36 & 0.02 \\
JAGALENE & 6 & -3.35 & 4.94 & 2.47 & -1.35 & 0.27 \\
OKFIELD & 4 & -3.38 & 8.56 & 3.50 & -0.97 & 0.38 \\
2174 & 6 & -3.76 & 3.39 & 1.38 & -2.71 & 0.04 \\
JAGGER & 6 & & & & & \\
& & & & & & \\
\hline & & & & & & \\
\end{tabular}


Table 4. Use of $\overline{\bar{D}} *$ to forecast changes in popularity of cultivars with wheat growers in Western Kansas, by year, over a five-year period.

\begin{tabular}{|c|c|c|c|c|c|c|c|c|c|c|}
\hline & 20 & & & 2006 & & 2007 & & 008 & & 009 \\
\hline CULTIVAR & $\overline{\bar{D}} *$ & RANK** & $\overline{\bar{D}}$ & RANK & $\overline{\bar{D}}$ & RANK & $\overline{\bar{D}}$ & RANK & $\overline{\bar{D}}$ & RANK \\
\hline JAGGER & $\overline{0.0}$ & 1 & 0.0 & 2 & $\overline{0.0}$ & 2 & $\overline{0.0}$ & 3 & $\overline{0.0}$ & 3 \\
\hline JAGALENE & 6.5 & 2 & 6.0 & 1 & 3.8 & 1 & 2.8 & 1 & 2.8 & 1 \\
\hline TAM 110 & 0.9 & 3 & 0.0 & 5 & -0.4 & & -0.9 & & -0.3 & \\
\hline TREGO & 2.3 & 4 & 0.9 & & 0.9 & & 1.3 & & & \\
\hline STANTON & -2.6 & 5 & -3.3 & & -4.2 & & -3.0 & & & \\
\hline TAM 111 & & & 6.8 & 4 & 3.3 & 3 & 5.1 & 2 & 5.0 & 2 \\
\hline IKE & -1.9 & & -2.3 & & -2.3 & 5 & -1.6 & & & \\
\hline TAM 112 & & & & & 8.8 & & 8.1 & 5 & 9.5 & 5 \\
\hline T81 & & & 2.5 & 3 & 1.7 & 4 & 0.8 & 4 & 1.2 & 4 \\
\hline
\end{tabular}

$* \overline{\bar{D}}=$ mean over seasons of means of DYA values over locations within a season, in bushels/acre, using data from seasons prior to the given year.

** Rank of "percent of seeded acres" in the given year.

Table 5. Use of $\overline{\bar{D}}$ to forecast changes in popularity of cultivars with wheat growers in southeastern and south-central Kansas, by year, over a five-year period.

\begin{tabular}{|c|c|c|c|c|c|c|c|c|c|c|}
\hline & & 005 & & 06 & 20 & & & 08 & & 09 \\
\hline CULTIVAR & $\overline{\bar{D}} *$ & $\mathrm{RANK}^{* *}$ & $\overline{\bar{D}}$ & RANK & $\overline{\bar{D}}$ & RANK & $\overline{\bar{D}}$ & RANK & $\overline{\bar{D}}$ & RANK \\
\hline JAGGAR & 0.0 & 1 & 0.0 & 2 & 0.0 & 2 & 0.0 & 3 & $\overline{0.0}$ & 5 \\
\hline JAGALENE & 8.1 & 2 & 6.6 & 3 & 5.7 & 3 & 4.9 & 2 & 3.7 & \\
\hline 2137 & 3.5 & 3 & 3.2 & 4 & 3.1 & 4 & 4.0 & 5 & 4.8 & \\
\hline 2174 & -1.7 & 4 & -1.7 & 5 & -2.0 & & -0.9 & & & \\
\hline OVERLEY & 11.8 & 5 & 9.6 & 1 & 7.9 & 1 & 7.1 & 1 & 6.5 & 1 \\
\hline OMEGA & -1.7 & & -1.5 & & -1.6 & 5 & -1.2 & & & \\
\hline SANTA FE & & & 7.7 & & 3.6 & & 7.3 & 4 & 7.5 & 2 \\
\hline FULLER & & & & & 1.5 & & 3.7 & 5 & 5.8 & \\
\hline POSTROCK & & & & & -1.8 & & 2.5 & & 4.9 & 4 \\
\hline
\end{tabular}

$* \overline{\bar{D}}=$ mean over seasons of means of DYA values over locations within a season, in bushels/acre, using data from seasons prior to the given year.

**Rank of "percent of seeded acres" in the given year. 